Currículo sem Fronteiras, v. 19, n. 3, p. 1410-1423, set./dez. 2019

\title{
SUCESSO EDUCATIVO: representações sociais dos alunos de dois prestigiados colégios privados portugueses
}

Maria Luísa Quaresma

Universidad Autónoma de Chile - UA

\begin{abstract}
Resumo
Este artigo analisa as representações de sucesso educativo partilhadas pelos alunos de dois prestigiados colégios privados de Lisboa. Após a discussão das distintas conceptualizações teóricas sobre o sucesso educativo, analisa-se a multidimensionalidade que o conceito adquire para estes jovens, que nele englobam, para além da tradicional vertente instrutiva, as vertentes cultural, cívica e social. Reflete-se ainda sobre a influência da socialização escolar nas suas representações de sucesso, vendo em que medida elas refletem quer o ideal de uma formação integral perseguido por ambos os colégios, quer as especificidades dos projetos educativos de cada um deles. Uma reconceptualização da noção de sucesso educativo na ótica das classes dominantes, eis a proposta deste artigo.
\end{abstract}

Palavras-chave: sucesso educativo; classes dominantes; colégios privados

\begin{abstract}
This article analyses representations of success shared by students at two prestigious private schools in Lisbon. It begins with a discussion of theoretical concepts of educational success, and then examines the multidimensional nature of this concept for the youths attending these schools. In addition to learning, these students refer to others, equally valued, dimensions of success, such as cultural, civic and social attainments. The article explores the influence of school socialization on representations of success, assessing the extent to which they reflect the ideal of a holistic education sought by both schools and the specific educational projects of each one. This article proposes a conceptualization of the idea of educational success from the perspective of the upper classes.
\end{abstract}

Keywords: educational success; upper classes; private schools 


\section{Introdução}

Neste artigo refletiremos sobre as representações sociais de sucesso educativo dos alunos de dois prestigiados colégios privados de Lisboa com longa tradição na preparação da elite do país, entendida - no sentido que lhe atribuem Savage et al (2013) - como a mais privilegiada classe social em termos de stock de capital económico, cultural e social. Assim, propomo-nos problematizar o sucesso educativo dum ângulo diferente daquele que tem sido privilegiado pela sociologia da educação - mais focalizada nos fatores familiares e/ou escolares que o promovem - e dando voz aos que detêm o papel principal no processo da sua construção: os alunos. Por um lado, motivou-nos o interesse em captar o significado que os alunos destes colégios atribuem ao sucesso educativo. A hipótese de ele ser entendido apenas como êxito académico era reforçada pelo facto de estarmos perante alunos de estabelecimentos de ensino cuja imagem de marca assenta na excelência académica e provenientes de famílias com metas educativas bem definidas para os filhos e que, enquanto consumidoras esclarecidas de escola, escolhem criteriosa e racionalmente os estabelecimentos de ensino com garantias de eficácia instrutiva (Van Zanten, 2009). Por outro lado, e na linha do preconizado por Veloso e Abrantes (2013), mobilizou-nos a possibilidade de contribuir para a "desconstrução" do conceito de sucesso educativo, que vem sendo redutoramente confinado aos resultados académicos mensuráveis através de testes e exames, num quadro de subordinação das lógicas escolares às políticas de accountability, responsáveis pela prevalência no campo escolar de uma "cultura ansiosa do resultado" (Baudelot e Establet, 2009, p.9). A curiosidade sociológica de penetrar num universo escolar cujo estudo tem sido ofuscado pela “considerável atenção” (Van Zanten, 2015, p.4) prestada à educação das classes desfavorecidas e que tem permanecido "na sombra” das investigações sociológicas portuguesas, constituiu também motivação para este estudo.

Num primeiro momento, problematizaremos teoricamente a noção de sucesso educativo enquanto conceito multidimensional que incorpora a vertente instrutiva, mas não se restringe a ela. Seguidamente, procederemos à descrição metodológica da nossa investigação, à identificação das metas educativas dos colégios e à caracterização sociográfica dos seus públicos. Por fim, partiremos à descoberta das representações sociais de sucesso partilhadas pelos alunos, analisando as dimensões em que ele se desdobra e em que medida elas são reflexo das experiências socializadoras escolares.

\section{Em torno do significado de sucesso educativo: abordagem teórica}

O conceito de sucesso está longe de suscitar consensualidade entre a comunidade científica. Lahire (2008) fala de uma noção imprecisa e de grande volatilidade, cujo sentido e consequências estão sujeitos às "variações históricas e sociais”, lembrando ainda, em linha com Berlin, Lévy-Garboua e Montmarquette (2012), que o conceito assume configurações diferentes em função da pertença social das famílias, com as classes populares a identificarem como sucesso escolar o que as classes superiores identificam como fracasso. Também Kuh 
et al. (2006) destacam a existência de múltiplas definições de sucesso, identificando como mais comuns as que remetem para indicadores quantificáveis de desempenho. De facto, o sucesso tem sido habitualmente circunscrito ao êxito na instrução (Cress et al., 2010), sendo definido através da aprovação de ano e/ou dos resultados nas disciplinas curriculares perspectiva aliás partilhada por organizações internacionais como a OCDE (Organização para a Cooperação e Desenvolvimento Económico) e que enforma, nomeadamente, as provas PISA (Programme for International Student Assessment). Em Portugal, é também este o critério adotado para definir as escolas de sucesso, identificadas através dum ranking nacional que abriu a porta à dicotomização qualitativa dos estabelecimentos de ensino e à expansão de uma política de mercadorização da educação (Ball, Bowe e Gewirtz, 1996; Afonso, 2013; Apple, 2005) com potencial impacto no aumento da segregação social e académica interescolas (Ball, Bowe e Gewirtz, 1996). Nesta acepção, o sucesso restringe-se à aquisição dos conteúdos cognitivos - avaliados através de testes e exames - e à certificação da formação.

No entanto, ao longo dos últimos anos o conceito de sucesso foi sendo alargado a novas dimensões (Kuh et al., 2006), a que não será alheia "a diversidade de concepções de vida e, portanto, de educação que coexistem numa sociedade pluralista” (Perrenoud, 2002, s/p.). Problematizar o sucesso implica, pois, refletir sobre essa multiplicidade de significados que dificultam a consensualidade sobre o que é “ser bem-sucedido", como constata Silva (2003) quando questiona: “deve privilegiar-se, na «medida» do êxito (...) a «excelência académica» convencional, assente em saberes organizados em disciplinas, por sua vez hierarquizadas em «maiores» e «menores», e quase umbilicalmente ligada à ideia de seleção rigorosa segundo o mérito? Ou deve preferir-se uma concepção larga de «arca de competências» a adquirir e de aprendizagens a realizar, nos vários domínios do conhecer, do fazer, do ser e do viver em comum?” (p.180).

Se é verdade que a escola não deverá “abrir mão de ensinar os conhecimentos disciplinares” (Perrenoud, 2005, p.73), também é verdade que a dimensão instrutiva não é o único parâmetro de avaliação de sucesso à luz de uma concepção mais ampla de educação e de uma conceptualização de escola enquanto locus educativo, cuja missão não se restringe ao desenvolvimento das competências cognitivas e cuja ação não é redutível às performances meramente escolares tributárias de uma concepção performativa da educação (Duru-Bellat, 2006; Ballion, 1991). Desenvolver todas as potencialidades do indivíduo é, na atualidade, a missão da educação. Ela é requerida não apenas pelo "défice de socialização da sociedade contemporânea” (Tedesco, 2008, p.34), mas também pela exigência dos novos modelos de produção, cuja competitividade requer agora "indivíduos completos", isto é, que aliem à formação para o trabalho a formação do cidadão e o desenvolvimento pessoal, traduzidos na "capacidade de trabalhar em equipa, gosto pelo risco, sentido de responsabilidade e de disciplina pessoal, sentido de decisão e compromisso, iniciativa, curiosidade, criatividade, espírito de profissionalismo, busca da excelência...” (Tedesco, 2008, p.59).

Para Creemers (1997), uma educação de sucesso pressupõe ainda o desenvolvimento de competências sociais e estéticas, importantes não apenas per se mas também pelo impacto positivo nos resultados académicos. Sendo a escola o espaço privilegiado de transmissão do "legado cultural da humanidade", o conceito de sucesso educativo alarga-se ainda às 
competências culturais e comunicacionais (Cress et al., 2010) responsáveis pela formação de homens cultos, isto é, indivíduos que adquiriram os saberes socialmente reconhecidos como dignos de interesse de índole intelectual ou estética e que estão apetrechados da utensilagem intelectual necessária para atribuir sentido à sua ação e encontrar nelas uma fonte de prazer intelectual e estético. Desta perspectiva, um aluno com sucesso terá internalizado as disposições intelectuais e artísticas que o tornarão receptivo não só para o "encontro - no sentido de contato, de aproximação empática e mesmo de «encontro amoroso» - com a obra de arte e outras formas de objetivação da cultura erudita, como (...) para a fruição «cultivada» das mesmas” (Pinto, 2007, p.159).

Demarcando-se também da concepção unidimensional de sucesso, Good e Brophy (1986) incluem no conceito a dimensão da assiduidade dos alunos e da aquisição de atitudes positivas perante a escola e os professores. Hutmacher (1995) contribui para o debate sobre o significado de sucesso integrando no perfil de escola de qualidade o desenvolvimento nos alunos de capacidades como saber-aprender, saber-analisar, refletir e compreender, saber relativizar conhecimentos e crenças, saber comunicar, argumentar, cooperar e criar. Remetendo também para o perfil do aluno bem sucedido, West e Hopkins (1996) defendem que a escola desenvolva nos alunos não apenas o auto-conhecimento e a auto-estima, mas também a capacidade de estabelecer relações e de assumir responsabilidades sociais, de participar num leque amplo de experiências humanas, como as de âmbito desportivo ou cultural, de se envolver no campo da cidadania e de assumir o seu papel na comunidade e na sociedade.

Uma educação para o exercício responsável da cidadania, para a solidariedade local e planetária, para a autonomia e para a responsabilidade nas múltiplas esferas da vida são, também para Perrenoud (2005), condição para que os jovens possam enfrentar a complexidade crescente do mundo. Num contexto de modernidade caracterizado pelo processo de individualização e pela reflexividade, o sucesso pressupõe a aquisição de "hábitos e ferramentas intelectuais que ajudem [os alunos] a compreender as implicações da [sua] ação e seu significado no que se refere a grandes princípios, como a solidariedade, justiça, democracia, respeito às diferenças ou ao meio ambiente” (Perrenoud, 2005, p.94). Para maior eficácia, a educação cidadã não se confinará a uma mera disciplina no curriculum. Ela será transversal a todas as disciplinas curriculares e perpassará todos os momentos e todos os espaços da vida escolar com virtualidades formativas - isto é, o espaço físico, relacional, organizacional e de relação pedagógica. A participação democrática nos órgãos formais de gestão, o envolvimento em atividades informais da vida escolar e na organização da própria aula constituirão oportunidades reais para os alunos exercitarem a cidadania e crescerem como cidadãos integrais (Perrenoud, 2005).

Noutro estudo, Alves (2010) desdobra o sucesso individual em cinco componentes: académica, relacional, comportamental e socioemocional. Outros projetos mais recentes, mas desenvolvidos em escolas e universidades de prestígio em Santiago do Chile ${ }^{1}$, dão conta também da multiplicidade de acepções que os atores educativos integram no conceito de sucesso (Quaresma, 2017). Na generalidade dos discursos, a dimensão instrutiva surge como um dos múltiplos sentidos atribuídos à excelência. Neste conceito integram ainda a vertente 
emocional, particularmente enfatizada pelos professores e que abarca tudo o que é relativo à subjetividade dos alunos no desenrolar do processo educativo, nomeadamente ao seu bemestar na escola e na sala de aula; a vertente comportamental, envolvendo a aquisição de atitudes que conduzam a uma integração bem sucedida na universidade e no mundo do trabalho; e, finalmente, a vertente valórica, relativa à internalização de valores de âmbito escolar, institucional, societal, cívico, mas também pessoal, como é o caso do esforço, da autosuperação, da autonomia e do espírito crítico.

O sucesso no seu sentido amplo e plural, cujos principais vetores problematizámos, é particularmente valorizado no topo da hierarquia social, onde as famílias têm a formação integral como desígnio socializador para os filhos, educados para integrar as fileiras da "(...) "verdadeira elite" que é apresentada como "total”, polimórfica e versátil, mais do que pura e simplesmente dotada de virtudes académicas” (Darchy-Koechlin et al, 2015 p.144). Pretendendo que os filhos "sejam felizmente e apesar de tudo melhor educados do que nos outros meios” (Mension-Rigau, 2007, p.103), estas famílias procuram em colégios social e escolarmente seletivos o enquadramento capaz de "assegurar, para lá da instrução propriamente dita, as tarefas de educação” (Pinçon e Pinçon-Charlot, 2007, p.84) e de, simultaneamente, dar continuidade às práticas socializadoras iniciadas no seio familiar. Nesses estabelecimentos de ensino, estas famílias encontram a garantia de uma formação de excelência em todos os domínios da pessoa total e de uma socialização nos valores do trabalho, do esforço, da disciplina e do mérito (Khan, 2011), mas também do respeito, da abertura e da dedicação ao outro - traços que acreditam marcar a fronteira de distintividade entre a educação dos seus herdeiros e a educação das massas, providenciada por uma escola pública que identificam com a "falta de um sistema de valores coerente” (Van Zanten 2009, p.190).

\section{Nos bastidores da investigação: opções metodológicas e caracterização dos colégios em estudo}

A nossa opção metodológica recaiu sobre o estudo de caso em dois colégios privados ${ }^{2}$ que recebem alunos desde o Infantário até à entrada na Universidade ( $12^{\circ}$ ano). Eles foram escolhidos segundo quatro critérios: a performance académica, avaliada pelos lugares de topo nos rankings escolares nacionais; a difusão de uma cultura de excelência e de mérito não só no plano instrutivo, mas também educativo; a longa tradição na formação das elites do país; a pertença dos alunos às classes cultural, social e economicamente dominantes. Com efeito, estamos perante mães e pais com elevadas qualificações académicas (respetivamente 38,1\% e 33,2\% são graduados; 23,8\% e 23,1\% têm mestrado, 12,1\% e 17,9\% são doutorados e 9,8\% e 10,6\% têm um pós-doutorado), integrados nas áreas profissionais da Engenharia, Medicina, Economia e Gestão e pertencentes à Burguesia Dirigente e Profissional (31,9\%), Burguesia Empresarial e Proprietária (20,8\%) e Pequena Burguesia Intelectual e Científica $(41,1 \%)^{3}$. Para tornar mais profícuo o confronto analítico, escolhemos estabelecimentos de ensino com matrizes ideológicas distintas: um colégio religioso, pertencente a uma ordem religiosa desde 
sempre ligada ao ensino, e um colégio laico, fundado há 80 anos por um reputado pedagogo e que desde então se mantém sob tutela da mesma família.

Apesar de terem "personalidades" distintas, estes colégios partilham a meta da excelência e da “formação integral do homem", preconizada nos respectivos Projetos Educativos. O colégio laico propõe-se formar os alunos em três vertentes: humana, desenvolvendo a autoestima, sentido crítico e analítico-reflexivo, a criatividade e autonomia; académica, valorizando o conhecimento do património linguístico, literário e científico; de cidadania, promovendo o desenvolvimento da consciência individual e coletiva e a participação na vida cívica. O colégio religioso define também, no seu Projeto Educativo, três pilares educativos: pessoal, formando alunos reflexivos, críticos, responsáveis, envolvidos no projeto escolar e receptivos ao ideal do magis inaciano (fazer mais e melhor); social, educando para a ação social, para o princípio de “serviço ao outro" e para os valores da solidariedade e caridade; religioso, acompanhando os alunos no seu crescimento da sua Fé. Partilhada pelos dois colégios é também a educação dos alunos numa cultura de trabalho, de rigor e de esforço, com forte expressão tanto nos discursos dos respectivos agentes educativos como nos Projetos Educativos e documentos afins.

Durante o trabalho de terreno, prolongado por três anos, acionámos técnicas quantitativas e qualitativas. Na fase exploratória, entrevistámos os representantes dos principais órgãos dos colégios e das suas Associações (de Pais, de Alunos e de Antigos Alunos); na fase principal, inquirimos 475 jovens do último ano do Ensino Básico e dos três anos do Ensino Médio (uma amostra representativa em termos de sexo, ano escolar e agrupamento cientifico), realizámos 19 entrevistas semi-diretivas a pais e ex-alunos e 4 grupos de discussão a estudantes e professores.

Neste artigo, centrar-nos-emos sobretudo nos dados relativos às representações de sucesso educativo obtidos junto dos alunos através do inquérito e dos grupos de discussão, procurando confirmar/infirmar a hipótese de os alunos partilharem uma concepção multidimensional de sucesso que refletirá a influência socializadora dos respetivos colégios.

\section{Cartografando as dimensões do sucesso educativo: representações sociais dos alunos}

Para os alunos destes dois colégios, o conceito de sucesso educativo contempla, inequivocamente, a aquisição dos conhecimentos disciplinares e a qualidade da formação académica, indo de encontro à concepção mais generalizada (Perrenoud, 2002) de sucesso como êxito na instrução. Este surge automaticamente associado ao tema “classificações”, face visível do desempenho académico cuja importância merece consensualidade entre estes alunos, protagonistas assumidos de “carreiras focadas” (Vieira, Pappamikail e Nunes, 2012). Como dirá um dos entrevistados, convicto do impacto do veredicto académico no delinear dos destinos escolares e profissionais "as notas é que vão dar acesso ao teu emprego, ao teu curso. A tanto... na tua vida” (aluno 5, colégio laico, 17 anos) 
Educados em sintonia pelas famílias e pelos colégios nos valores do trabalho, da exigência e da autosuperação, os inquiridos integram na sua representação de sucesso a obtenção de elevadas classificações e o ingresso nos cursos superiores pretendidos (95,3\%), que estão maioritariamente entre os que dão acesso às trajetórias profissionais mais promissoras em termos de sucesso social e económico - caso das ciências económicas, da medicina e das engenharias (Quaresma, 2014). As elevadas expectativas em termos de percurso académico (99,1\% pretendem ingressar na universidade, onde 66,6\% projetam tirar doutoramento e pós-doutoramento) e o peso das classificações num contexto de apertado numerus clausus de acesso aos mais prestigiados cursos e estabelecimentos universitários contribuirão para que apenas uma escassa percentagem de alunos $(18,4 \%)$ esteja totalmente de acordo com a afirmação de que ter sucesso é apenas “cumprir os requisitos mínimos” para transitar de ano letivo. Tendo naturalizado a hierarquia da excelência introduzida pelo mecanismo de numerus clausus, estes alunos entram no jogo da competição académica, percepcionando as altas classificações como garantia de uma boa preparação não apenas para o ensino superior, mas também para exercer a profissão ambicionada. A concretização dos sonhos emerge como uma dimensão subjetiva do sucesso, que $97 \%$ dos inquiridos integra também no conceito em análise e que ganha pertinência tendo em conta a possibilidade de, para alguns alunos, o sucesso escolar "vir a revelar-se responsável por alguns fracassos existenciais - quando a excelência escolar obtida dita a inevitabilidade de (per)cursos não verdadeiramente desejados” (Vieira, Pappamikail e Nunes, 2012, p.48). No seu conceito de sucesso, os alunos incluem também características pessoais particularmente valorizadas e estimuladas pelas famílias e pelos colégios, como pudemos testemunhar durante as entrevistas a pais, professores e diretores, como ser "exigente consigo e empenhado nos seus projetos, fazendo sempre mais e melhor para alcançar os seus objetivos” (98,5\%). Estes atributos inscrevem-se nessa ficção necessária (Dubet, 2004, p.35) que é a meritocracia, um princípio fundamental e consensual da sociedade democrática que se encontra ao serviço da legitimação das desigualdades e que tem na escola um espaço privilegiado de inculcação (Tenret, 2008). Evidenciando sinais de adesão à crença meritocrática, estes alunos escamoteiam o facto de os resultados não serem um mero produto dos traços individuais (Khan, 2011) e identificam o sucesso com as capacidades de "trabalho, esforço, rigor e autosuperação”, assim legitimando a convicção de que cada um tem o que merece e merece aquilo que tem (Lerner, 1980). Para a quase totalidade (96,2\%) dos inquiridos, esses valores terão de integrar o ethos de qualquer escola que tenha como meta o sucesso dos alunos e a sua preparação para enfrentar os desafios do competitivo mercado laboral que os espera à saída da Universidade. Como explica um dos jovens entrevistados, pondo em contraste a ética de trabalho do seu colégio com o alegado laxismo de algumas outras escolas, "lá fora tenho amigos que têm uma, duas aulas por dia! Como é que eles depois vão trabalhar? Se calhar, nos primeiros anos vão trabalhar 10 horas por dia, como é que se vão aguentar?” (aluno 3, colégio religioso, 17 anos).

Mas os inquiridos não restringem o sucesso à performance instrutiva, tal como acontece, aliás, no estudo anteriormente referenciado sobre a realidade das escolas de prestígio chilenas. De acordo com os resultados, a dimensão académica - relacionada com ser o melhor 
aluno da turma, entrar na melhor universidade do país e num curso de prestígio e estudar muitas horas - é referida a par de outras, como as que envolvem a internalização do valor do esforço e da superação, tão conformes à doxa meritocrática, ou o desenvolvimento da capacidade reflexiva e do sentido humanista, como ser crítico e reflexivo ou viver num país onde todos tenham igualdades de oportunidades. Em sintonia com esta visão multifacetada, um dos jovens entrevistados faz questão de sublinhar: "o sucesso educativo é não só ter boas notas, conseguirmos entrar na faculdade que queremos e ter um futuro com o sucesso desejado, mas também formarmo-nos como cidadãos e como pessoas” (aluno 1, colégio religioso, 16 anos). Nesta formação como "pessoa", os alunos integram a internalização das disposições culturais e estéticas necessárias à fruição do património cultural (Ballion, 1991), confirmada pela literatura como uma prioridade formativa neste universo social, onde a abertura disposicional das crianças à cultura cultivada se inicia no contexto familiar através das mais variadas práticas informais (Mension-Rigau, 2007). Isto ajudará a entender que, para uma ampla maioria dos inquiridos (70,3\%), o sucesso seja também entendido como "interesse pelas artes, literatura e ciência" - uma opinião que, no entanto, conta com menor adesão no colégio religioso $(60,7 \%)$ do que no laico $(75,2 \%)$, por razões que se prenderão com a forte matriz cultural deste último estabelecimento e com a marca que ela poderá imprimir nos seus alunos. Com efeito, como diz com orgulho um dos mais antigos professores do colégio, "esta é uma escola que nasceu de gente da Cultura" e que faz questão de manter vivo esse traço identitário, procurando cumprir o que Meirieu (2014) considera ser uma das funções prioritárias da escola: promover a educação artística e cultural de modo a fazer emergir nos alunos a procura da arte e da cultura e a promover esse "encontro amoroso" entre eles de que fala Pinto (2007). A dinamização de uma orquestra de câmara e de um coral, as sessões dedicadas à poesia e à declamação, a realização de Semanas Temáticas consagradas às Artes, à Literatura ou à Ciência são exemplos de iniciativas que se enquadram nesta perspectiva. Em convergência com as propostas de Bourdieu (1987) para o ensino do futuro, este colégio abre-se ao exterior e traz até aos alunos os agentes e criadores culturais, evitando "que o ensino escolar constitua um universo separado, sagrado, capaz de fornecer uma cultura igualmente sagrada e distanciada do quotidiano" (1987, p.117) e, ao mesmo tempo, potencializando as condições para uma maior receptividade dos alunos a um património cultural que também cabe à escola divulgar e ensinar a fruir: "Temos imensas conferências, temos a Semana de Línguas, vêm cá personalidades, vêm-nos dar lições de História... é muito importante termos essa noção e mais cultura, para podermos singrar na vida" (aluno 5, colégio laico, 17 anos).

Uma outra componente que os alunos englobam na sua representação social de sucesso prende-se com a tolerância, a participação na vida social e cívica e a solidariedade (81,9\%), quer em benefício da sociedade (68,2\%), quer em benefício próprio (63,6\%) A apresentação de razões simultaneamente altruístas e instrumentais para justificar o envolvimento em atividades solidárias é também documentada por Holdsworth (2010), que a propósito do voluntariado identifica nos alunos a vontade de ajudar os outros e, ao mesmo tempo, de adquirir competências que sejam uma mais valia para a futura carreira. No caso concreto destes alunos, tal ambivalência não deixará de ser potenciada pela exposição a princípios de 
socialização contraditórios (Lahire, 2008): a educação nos valores do altruísmo e do “espírito de serviço" que integram o ethos destes colégios e destas classes sociais (Pinçon and PinçonCharlot, 2007) e, simultaneamente, nos valores individualistas e pragmático-instrumentais do sucesso e do mérito, considerados por estes alunos tanto mais indispensáveis quanto, como diz um deles, a vida "tem competitividade ao extremo. Podem dizer que é um exagero, podem dizer que a vida não está certa ao ter esse lado extremo, mas é assim e nós temos de nos adaptar à realidade. Não vale a pena dizer se é demais ou não” (aluno 3, colégio religioso, 17 anos). E embora os alunos destes colégios já disponham de múltiplos trunfos relativamente à generalidade dos “concorrentes" para um bom posicionamento na competição que os espera, o voluntariado não deixará de ser uma mais valia no curriculum em termos de empregabilidade (Anderson e Green, 2012).

Para a adesão dos alunos a estes valores não será indiferente a sensibilidade destes dois colégios ao contributo da educação no desenvolvimento da participação social e cidadã, em declínio nos países da OCDE (Campbell, 2006) e que se traduz na formação de "cidadãos conscientes, que pensem pela sua cabeça, que lutem pelas suas ideias, tolerantes, responsáveis e com grande sentido cívico” (Diretora, colégio laico). O estudo de Howard (2013) dá conta da importância atribuída por este tipo de estabelecimentos de ensino ao envolvimento dos seus alunos em atividades da comunidade local, nomeadamente através do voluntariado. Adotada em nome da formação do carácter (Holt, 2008), esta abertura ao outro encerrará propósitos menos altruístas, segundo alguns investigadores. Enquanto Kenway (2013) vê nela uma expiação de culpa por parte de quem se sente privilegiado, outros percepcionam-na como uma legitimação do privilégio com vista à sua preservação: Howard (2013) fala de uma estratégia para mostrar que os seus privilégios são postos ao serviço dos desfavorecidos e Holdsworth (2010) de promoção de uma imagem positiva destes colégios junto da comunidade.

São os alunos do colégio religioso que mais se dizem estimulados a participar na vida social e cívica, em conformidade com a matriz católica desta escola e com uma aposta mais forte nas atividades de Trabalho Social e de Voluntariado do que a verificada no colégio laico. O contributo para a comunidade é, aliás, um dos elementos da definição de sucesso obtida por Enke e Ropers-Huilman (2010) junto de alunos de estabelecimentos de ensino católicos, que partilham com o colégio português a vivência dos "valores comunitários, voluntarismo e justiça social” (Enke e Ropers-Huilman, 2010, p.13). Como diz um dos alunos do colégio religioso, o seu estabelecimento de ensino educa "para termos uma profissão, para irmos para a faculdade, mas educa-nos também para não nos focarmos só nisso, para nos preocuparmos com os outros. É o Educar para Servir”. (aluno 6, colégio religioso, 17 anos).

O desenvolvimento da autonomia, da responsabilidade e do sentido crítico e reflexivo, bem como da capacidade de tomar posição sobre os valores e regras dos respectivos colégios, figuram também na representação de sucesso destes alunos (81.1\%). Mas se é certo que o desenvolvimento nos alunos do seu espírito crítico envolve "o risco de que este se exerça antes de tudo contra a escola” (Perrenoud, 2005, p.132), esse perigo dir-se-ia reduzido nestes colégios, a avaliar por uma outra característica identificada com o sucesso: “agir de acordo com as normas e valores da escola para não ser prejudicado no seu projeto escolar” (62.6\%). 
Tal significa uma "acomodação” à normatividade escolar que encerra um potencial de conflitualidade com o exercício da reflexividade e do espírito crítico, instrumentalmente "sacrificados" em nome do valor maior que representa para estes alunos o projeto escolar. O conformismo é mais vincado nos alunos do colégio religioso, uma instituição de matriz mais conservadora do que o colégio laico. É aliás no colégio confessional que encontramos nos alunos uma postura de maior compreensão perante a resistência institucional ao exercício da sua autonomia, que eles justificam: “o colégio tem muitos anos e tem um ideário e percebo que seja complicado aceitar novas realidades. O colégio tem 60 anos de idade e qualquer proposta nova que pode mexer com o ritmo do colégio, assusta” (aluna 2, 17 anos).

Em linha com a teorização de Tinto (1993), estes jovens incorporam também na sua representação de sucesso educativo a vertente social, em que aquele investigador integra as relações entre alunos e que nos propusemos alargar à relação entre toda a comunidade educativa. Com efeito, 85,5\% dos inquiridos veem como dimensão de sucesso o "dar-se bem com colegas, professores e funcionários e ser feliz na escola”, objetivo este que é proporcionado aos alunos pelos respetivos colégios, a crer na percentagem residual de 3,6\% que não se diz feliz no seu habitat escolar. A maioria dos inquiridos vê mesmo o seu colégio como uma "grande família" (73,5\%) com a qual mantêm e continuarão a manter laços de vinculação afetiva, remetendo para a metáfora da "happy family" (Beare, Caldwell, e Millikan, 1989, p.189) e das “escolas-casulo", onde "se vive em vaso fechado no plano afetivo e que eles [os alunos] teriam dificuldade em abandonar” (Viaud, 2005, p. 164). Antevendo a entrada na Universidade, os inquiridos falam da "nostalgia” da partida, admitindo viver protegidos numa "caixinha” (aluno2, colégio laico, 17 anos) e ter receio de encontrar um mundo hostil para lá dos muros do atual colégio: “Quando sairmos daqui vamos sentir-nos um bocado desamparados”, diz-nos um aluno (aluno 5, colégio laico, 17 anos), lembrando os momentos de convívio que extravasam as interações formais “institucionalizadas”. Cerimónias, rituais, artefatos e memorabilia (Festas das Famílias, jantares e fins-de-semana de turma, divulgação em cartaz dos aniversariantes do dia, Livro dos Antigos Alunos) sedimentam uma forte afiliação com a escola (Beare, Caldwell e Millikan, 1989) e ajudam a construir um “espírito de corpo e um orgulho na instituição” (p. 196) que é visível nas palavras dos Antigos Alunos.

A imersão destes alunos em culturas fortes e personalistas, como a destes colégios, ajudará a compreender que uma escola de sucesso seja para eles sinónimo de "uma segunda família” (86,8\%). Esta definição é partilhada por 49,6\% dos que frequentam os colégios desde o Infantário e apenas por 26,9\% dos que ingressaram no Ensino Secundário, o que indicia o peso das trajetórias de fidelidade na importância conferida ao sentido de pertença à comunidade escolar enquanto dimensão do sucesso.

Em síntese, o sucesso educativo não se esgota, pois, na dimensão académica, como faz questão de afirmar o Diretor da escola religiosa, estabelecendo uma distinção clara entre as performances escolares e a formação humana: o "sucesso académico será o objetivo de levar os alunos a adquirirem o máximo de conhecimentos e pô-los em prática. O sucesso educativo tem que ver com a pessoa toda”, ou seja, com a vertente social, cultural e cívica, mas também, no colégio confessional, com a vertente religiosa. Só uma educação holística responderá ao 
desígnio destes colégios e das famílias que os procuram: "formar uma elite, o que requer um nível de sucesso educativo que já ultrapasse muito as outras escolas” (aluno 4, colégio laico, 17 anos). Tanto mais necessário quanto, como nos diz o mesmo aluno, "nós vamos ser as pessoas que vão estar à frente do país”

\section{Conclusão: redefinindo do conceito de sucesso educativo}

Para os alunos destes dois colégios, o conceito de sucesso educativo abarca a pluridimensionalidade requerida a quem se sente destinado a ter papéis de relevo na vida social, económica, política e cultural do país. Nele incluem aquela que é uma missão inquestionável da escola - a instrução -, acreditando que em tempos de democratização escolar apenas uma formação académica de excelência poderá garantir vantagens posicionais nas suas trajetórias escolares e profissionais. Mas no conceito de sucesso integram também outros pilares formativos tão valorizados quanto o académico, como é o caso da formação cultural, cívica, social e ainda religiosa, no caso do colégio confessional.

$\mathrm{Na}$ perspectiva destes alunos, ser bem-sucedido significa alcançar as elevadas classificações escolares que lhes garantem o acesso ao curso superior pretendido e ter interiorizado os valores da excelência, do rigor, da responsabilidade e da autossuperação em que foram educados, em sintonia, por famílias e colégios (dimensão académica). Mas significa também ter interesse pelas artes e pela cultura (dimensão cultural), estar desperto para os valores da solidariedade, intervir na vida cívica e ter capacidade reflexiva e espírito crítico (dimensão cívica) e ainda sentir-se integrado e feliz no colégio, que eles percepcionam como uma segunda família (dimensão social).

A concepção pluridimensional de sucesso destes alunos reflete, afinal, as influências socializadoras dos colégios, ambos apostados em assegurar a continuidade e o reforço do ideal de formação da "pessoa inteira” perseguido pelas classes dominantes e iniciado no contexto familiar. A valorização diferencial da dimensão cultural e cívica do sucesso dá também provas dessa sintonia dos alunos com o ethos e o modus operandi do colégio frequentado: os da escola laica, socializados num colégio que "nasceu de gente da cultura" e que promove um alargado leque de atividades culturais, põem a ênfase na dimensão cultural; os da escola religiosa, educados segundo o lema “educar para servir” e numa instituição que aposta na promoção de atividades de “serviço ao outro”, atribuem mais valor à dimensão cívica.

Assim, partindo da interseção entre as teorizações sociológicas e os resultados empíricos, redefinimos o conceito de sucesso educativo, integrando nele quatro polos analíticos académico, social, cultural e cívico - e procurando contribuir, ao mesmo tempo, para a reflexão sobre dois temas ainda pouco explorados pela sociologia: a polissemia deste conceito e a educação em colégios de elite. 


\section{Notas}

1. Projetos de investigação financiados por CONICYT, Fondecyt Regular Nr. 1170371 (Las elites académicas universitarias en Chile. Un estudio sobre los perfiles, vivencias y percepciones sobre el éxito del alumnado y el rol de las instituciones universitarias de élite en los procesos de reproducción y movilidad social) e Fondecyt iniciación Nr. 11140241 (La excelencia académica en escuelas públicas de prestigio: percepciones, vivencias y prácticas de los actores escolares)

2. Projeto financiado Fundação para a Ciência e Tecnologia (FCT SFRH / BD / 39952 / 2007).

3. Lugares de classe identificados através da combinatória entre dimensão profissional e cultural.

\section{Bibliografia}

AFONSO, Almerindo. Mudanças no Estado-Avaliador: comparativismo internacional e teoria da modernização revisitada. Revista Brasileira de Educação, Rio de Janeiro: ANPEd, v. 18, n. 53, p. 267-284, abr./jun. 2013.

ALVES, José. O projeto Fénix e as condições de sucesso. In: AZEVEDO, Joaquim, ALVES, José (Ed.). Projecto Fénix - Mais sucesso para todos. Memórias e dinâmicas de construção do sucesso escolar. Porto: Faculdade de Educação e Psicologia da Universidade Católica, 2010.

ANDERSON, Pauline, GREEN, Pat. Beyond CV building: the communal benefits of student volunteering. Voluntary Sector Review, Birmingham: University of Birmingham, v. 3, n. 2, p.247-256, jul. 2012.

BALL, Stephen, BOWE, Richard, GEWIRTZ, Sharon. School choice, social class and distinction: the realization of social advantage in education. Journal of Education Policy, Londres: Routledge, v. 11, n. 1, p. 89-112, jan. 1996.

BALLION, Robert. La bonne école. Paris: Hatier, 1991.

BAUDELOT, Christian, ESTABLET, Roger. L’élitisme républicain. L’école française à l'épreuve des comparaisons internationales. Paris: Éditions du Seuil, 2009.

BEARE, Hedley, CALDWELL, Brian, MILLIKAN, Ross. Creating an excellent school: some new management techniques. Londres: Routledge, 1989.

BERLIN, Noémi, LEVY-GARBOUA, Louis, MONTMARQUETTE, Claude. L'influence de l'origine sociale sur le niveau d'aspiration et la réussite scolaire. Project report. Montréal: CIRANO, 2012.

BOURDIEU, Pierre. Propostas para o ensino do futuro. Cadernos de Ciências Sociais, Porto: Afrontamento, n. 5, p.101-120, jul. 1987.

CAMPBELL, David. What is education's impact on civic and social engagement?. In: DESJARDINS, Richard, SCHULLER, Tom (Ed.). Measuring the Effects of Education on Health and Civic Engagement: Proceedings of the Copenhagen Symposium. OECD, 2006.

CREEMERS, Bert. Towards a theory of education effectiveness. In: HARRYS, Alma, BENNETT, Nigel, PREEDY,Margaret (Ed.). Organizational effectiveness and improvement in education. Buckingham: Open University Press, 1997.

CRESS, Christine. et al. Promising connection: Increasing college access and success through civic engagement. Boston: Campus Compact, 2010.

DARCHY-KOECHLIN, Brigitte, DRAELANTS, Hugues, TENRET, Élise. National and international student's definitions of merit in French Grandes Écoles. In: VAN ZANTEN, Agnès, BALL, Stephen, DARCHY-KOECHLIN, Brigitte (Ed.). Elites, privilege and excellence. The national and global redefinition of educational advantage. New York: Routledge, 2015.

DUBET, François . L'école des chances: qu'est ce qu'une école juste ?. Paris: Éditions Seuil, 2004.

DURU-BELLAT, Marie. L'inflation scolaire. Paris: Éditions du Seuil et la République des Idées, 2006. 
ENKE, Kathryn, ROPERS-HUILMAN, Rebecca. Defining and Achieving Success: Perspectives from Students at Catholic Women's Colleges. Higher Education in Review, Pensylvania: Pennsylvania State University, n. 7, p. 1-22, fev. 2010.

GOOD, Thomas. JERE, Brophy. School effects. In: WITTROCK Merlin (ed.). Third Handbook of Research on Teaching. New York: Macmillan, 1986.

HOLDSWORTH, Clare. Why volunteer? Understanding motivations for student volunteering. British Journal of Educational Studies, Londres: Routledge, v. 58, n. 4, p. 421-437, dez. 2010.

HOLT, Jenny. Public School Literature, Civic Education and the Politics of Male Adolescence. Aldershot: Ashgate, 2008.

HOWARD, Adam. Negotiating privilege through social justice efforts. In: MAXWELL Claire, AGGLETON, Peter (Ed.). Privilege, agency and affect: understanding the production and effects of action. Basingstoke: Palgrave, 2013.

HUTMACHER, Walo. A escola em todos os seus estados: das políticas de sistemas às estratégias de estabelecimento. In: NÓVOA, António (Ed.). As organizações escolares em análise. Lisboa: Publicações Dom Quixote, 1995.

KENWAY, Jane. The gift economy of elite schooling. International Studies In The Sociology Of Education Conference. Londres, 2013.

KHAN, Shamus. Privilege The making of an adolescent elite at St Paul' School. New Jersey: Princeton University Press, 2011.

KUH, George. [et al.]. What Matters to Student Success: A Review of the Literature. National Postsecondary Education Cooperative (NPEC). Recuperado de https://nces.ed.gov/npec/pdf/Kuh_Team_ExecSumm.pdf, 2006.

LAHIRE, Bernard. Sucesso escolar nos meios populares: as razões do improvável. São Paulo: Editora Ática, 2008.

LERNER, Melvin. The belief in a just world: a fundamental delusion. New York: Plenum Press, 1980.

MEIRIEU, Philippe. L'éducation artistique et culturelle une pédagogie de l'ébranlement. La Scène, Nantes: M. Médias, n. 32, p. 28-33, mar./mai. 2014.

MENSION-RIGAU, Eric. Aristocrates et grands bourgeois. Perrin: Éditions Plon, 2007

PERRENOUD, Philippe. Réussir à l'école: Tout le curriculum, rien que le curriculum!. 10ème Colloque De L'association Des Cadres Scolaires Du Québec. Québec, 2002.

PERRENOUD, Philippe. Escola e cidadania: o papel da escola na formação para a democracia. Porto Alegre: Artmed Editora, 2005.

PINÇON, Michel, PINÇON-CHAR.LOT, Monique. Sociologie de la bourgeoisie. 3. Ed. Paris: La Découverte, 2007.

PINTO, José. Indagação científica, aprendizagens escolares, reflexividade social. Porto: Edições Afrontamento, 2007.

QUARESMA, Maria. Entre o herdado, o vivido e o projetado. Estudo de caso sobre o sucesso educativo em dois colégios privados frequentados pelas classes dominantes. Porto: Edições Afrontamento, 2014.

QUARESMA, Maria. Excellence in High-Performing Public Schools in Chile. Schools Studies in Education, Chicago: University of Chicago Press, vol. 14, n. 1, p. 28-53, Spring 2017.

SAVAGE Mike. [et al.]. A new model of social class? Findings from the BBC' Great British Class Survey Experiment. Sociology, Thousand Oaks: Sage, v. 47, n. 2, p. 219-250, abr. 2013.

SILVA, Augusto. "Acesso» e «sucesso»: factos e debates na democratização da educação em Portugal. In: VIEIRA, Maria, PINTASSILGO, Joaquim, MELO, Benedita (Ed.). Intenções e apropriações. Lisboa: Centro de Investigação em Educação, 2003 
TEDESCO, Juan. O novo pacto educativo: educação, competitividade e cidadania na sociedade moderna. Gaia: Fundação Manuel Leão, 2008.

TENRET, Élise. L'école et la croyance en la méritocratie. Tese (doutorado) -Institut de recherche sur l'éducation. Université de Bourgogne: Dijon, 2008.

TINTO, Vincent. Leaving college. Rethinking the causes and cures of student attrition. Chicago: The University of Chicago Press, 1993.

VAN ZANTEN, Agnès. Educating elites. The changing dynamics and meanings of privilege and power. In: VAN ZANTEN, Agnès, BALL, Stephen, DARCHY-KOECHLIN, Brigitte (Ed.). Elites, privilege and excellence. The national and global redefinition of educational advantage. New York: Routledge, 2015.

VAN ZANTEN, Agnès. Choisir son école. Stratégies familiales et médiations locales. Paris: PUF, 2009.

VELOSO, Luísa, ABRANTES, Pedro. (Orgs.). Sucesso escolar - da compreensão do fenómeno às estratégias para o alcançar. Lisboa: Editora Mundos Sociais, 2013.

VIAUD, Marie-Laure. Des collèges et des lycées différents. Paris: PUF, 2005.

VIEIRA, Maria, PAPPAMIKAIL, Lia, NUNES, Cátia. Escolhas escolares e modalidades de sucesso no ensino secundário: percursos e temporalidades. Lisboa, ISCTE, Sociologia Problemas e Práticas, Lisboa: ISCTE, n. 70, p. 45-70, set./dez. 2012.

WEST, Mel., HOPKINS, David. Reconceptualising school effectiveness and school improvement. American Educational Research Association Annual Meeting "School Improvement And School Effectiveness: Towards A New Synthesis”. New York, 1996.

\section{Correspondência}

Maria Luísa Quaresma: Professora da Universidad Autónoma de Chile e pesquisadora do Instituto de Estudios Sociales y Humanísticos da mesma universidade. Pesquisadora responsável de um projeto financiado por Conicyt (Fondecyt Regular Nr. 1170371).

E-mail: quaresma.ml@gmail.com

Texto publicado em Currículo sem Fronteiras com autorização da autora 